\title{
DETERMINAN KEJADIAN DIARE PADA BALITA DI PUSKESMAS RAWAT INAP SIMPANG TIGA KOTA PEKANBARU
}

\author{
Astria Megawati ${ }^{1}$, Buchari Lapau ${ }^{2}$, Agus Alamsyah ${ }^{2}$ \\ 1. Mahasiswa Prodi Magister Kesehatan Masyarakat STIKes Hang Tuah Pekanbaru, Riau, \\ Indonesia \\ 2. Dosen Prodi Magister Kesehatan Masyarakat STIKes Hang Tuah Pekanbaru, Riau, \\ Indonesia \\ Email : astriamega25@gmail.com
}

\begin{abstract}
Abstrak
Diare ialah buang air besar dengan konsistensi yang lebih encer/cair dari biasanya sebanyak lebih dari 3 kali per hari yang dapat/tidak disertai dengan lendir atau darah yang timbul secara mendadak dan berlangsung kurang dari 2 minggu. Di Puskesmas Rawat Inap Simpang Tiga tahun 2016 proporsi kejadian diare pada balita sebesar 6,3\%. Jumlah ini meningkat dibandingkan proporsi kejadian diare pada balita tahun 2015 yaitu sebesar 4,1\%. Tujuan penelitian adalah diketahuinya determinan kejadian diare pada balita di Puskesmas Rawat Inap Simpang Tiga Kota Pekanbaru Tahun 2018. Penelitian ini merupakan penelitian Studi Kasus Kontrol. Populasi kasus adalah seluruh balita penderita Diare dari bulan Januari 2017 s/d bulan April 2018 yang berjumlah 262 balita dan populasi kontrol adalah seluruh kasus bukan Diare pada tahun yang sama yang berjumlah 5.760 balita dengan jumlah sampel 195 kasus dan 195 kontrol. Analisis data yang dilakukan adalah analisis univariat, bivariat dan multivariat. Berdasarkan hasil analisis multivariat, variabel yang paling berpengaruh dengan kejadian diare pada balita di Wilayah Kerja Puskesmas Rawat Inap Simpang Tiga Kota Pekanbaru Tahun 2018 adalah kebiasaan cuci tangan pakai sabun (OR = 7,9 CI 95\% = $4,755-13,179)$, pekerjaan ibu (OR = 2,6 CI 95\% = 1,600-4,408) dan pendapatan (OR = 2,9 CI $95 \%=1,723-4,973)$. Disarankan kepada seluruh petugas kesehatan agar selalu melakukan penyuluhan rutin tentang pencegahan diare pada balita dan pentingnya cuci tangan pakai sabun terutama kepada ibu yang bekerja dan keluarga dengan pendapatan rendah.
\end{abstract}

Kata Kunci : Kejadian Diare, Kebiasaan Cuci Tangan Pakai Sabun, Pekerjaan Ibu, Pendapatan keluarga, Puskesmas Simpang Tiga Pekanbaru

\section{PENDAHULUAN}

Diare ialah buang air besar dengan konsistensi yang lebih encer/cair dari biasanya sebanyak lebih dari 3 kali per hari yang dapat/tidak disertai dengan lendir atau darah yang timbul secara mendadak dan berlangsung kurang dari 2 minggu. Sebagian besar penyakit diare bersifat akut dan biasanya berlangsung tidak lebih dari 3-5 hari (Syamsyudin, 2016).
Data WHO pada tahun 2011 menyatakan kematian anak di bawah 5 tahun mencapai angka 6,9 juta anak dan $14 \%$ dari kematian tersebut disebabkan oleh diare. Diperkirakan 2,5 miliar anak di bawah umur 5 tahun menderita tiap tahunnya di seluruh dunia, lebih dari setengah kasus ini terjadi di Asia dan Afrika (Hannif, dkk, 2011).

Penyakit diare merupakan penyakit endemis dan juga penyakit potensial KLB yang sering dijumpai dengan kematian di 
Indonesia. Menurut Riskesdas 2007, diare merupakan penyebab kematian nomor satu pada bayi $(31,4 \%)$ dan pada balita $(25,2 \%)$. Angka kesakitan diare pada tahun 2012 untuk semua umur sebesar 214 per 1.000 penduduk dan angka kesakitan diare pada balita 900 per 1.000 penduduk. Period prevalence diare pada Riskesdas 2013 (3,5\%) lebih kecil dari Riskesdas 2007 (9,0\%) (Kemenkes RI, 2013).

Insiden diare Provinsi Riau pada tahun 2013 sebesar 2,3\% dan period prevalence diare sebesar $5,4 \%$ untuk seluruh kelompok umur. Berdasarkan karakteristik, kelompok umur balita adalah kelompok umur yang paling tinggi menderita diare dengan jumlah Insiden diare balita di Riau sebesar 8,1\% (Kemenkes RI, 2013). Berdasarkan Rencana Strategis (Renstra) Dinas Kesehatan Provinsi Riau Tahun 2014-2019 diare merupakan salah satu penyakit yang masuk ke dalam program Pengendalian Penyakit Menular Langsung (Dinas Kesehatan Provinsi Riau, 2014).

Jumlah diare masih menjadi permasalahan di Kota Pekanbaru. Berdasarkan laporan Dinas Kesehatan Kota Pekanbaru terjadi peningkatan kejadian diare. Pada tahun 2015 kejadian diare sebanyak 2.390 kasus meningkat pada tahun 2016 yaitu sebanyak 3.479 (Dinkes Kota Pekanbaru Tahun 2015 dan 2016).

Diare pada bayi atau anak merupakan salah satu alasan umum yang membuat orangtua membawa anaknya ke dokter. Dikatakan bahwa anak di bawah usia 2 tahun mengalami diare dua sampai tiga kali diare setiap tahunnya dan sekitar $85 \%$ dari kejadian diare pada anak adalah diare akut. Angka kematian dilaporkan sekitar 8 dari 1000 anak dan kebanyakan disebabkan oleh dehidrasi. Diare masih merupakan problem kesehatan utama pada anak, terutama di negara berkembang seperti Indonesia. Sanitasi dan kebersihan lingkungan yang buruk merupakan faktor yang menyebabkan masih tingginya tingkat kejadian diare pada anak di Inodnesia (Sofwan, 2010).

Faktor risiko diare dibagi menjadi 3 yaitu faktor karakteristik individu, faktor perilaku pencegahan, dan faktor lingkungan. Faktor karakteristik individu yaitu umur balita, status gizi, dan tingkat pendidikan pengasuh balita. Faktor perilaku pencegahan diantaranya, yaitu perilaku mencuci tangan sebelum makan, mencuci peralatan makan sebelum digunakan, mencuci bahan makanan, mencuci tangan dengan sabun setelah buang air besar, dan merebus air minum, serta kebiasaan memberi makan anak di luar rumah. Faktor lingkungan meliputi kepadatan perumahan, ketersediaan sarana air bersih (SAB), pemanfaatan $\mathrm{SAB}$, dan kualitas air bersih (Utami, dkk, 2016).

Menurut Wijoyo (2013) faktor risiko diare terdiri dari faktor pendidikan, faktor pekerjaan, faktor umur balita, faktor lingkungan, faktor gizi, faktor sosial ekonomi, faktor makanan/minuman yang dikonsumsi dan faktor terhadap laktosa (susu sapi). Berdasarkan hasil penelitian Hastuti (2015) terdapat hubungan antara pengetahuan ibu dan kebiasaan ibu mencuci tangan dengan kejadian diare pada balita di wilayah kerja Puskesmas Pameungpeuk Kabupaten Bandung.

Puskesmas Rawat Inap Simpang Tiga merupakan puskesmas tiga terbesar dengan kejadian diare pada balita. Tahun 2016 proporsi kejadian diare pada balita di Puskesmas Rawat Inap Simpang Tiga sebesar 6,3\%. Jumlah ini meningkat dibandingkan proporsi kejadian diare pada balita tahun 2015 yaitu sebesar 4,1\%. 
(Dinas Kesehatan Kota Pekanbaru Tahun 2015 dan 2016). Berdasarkan latar belakang tersebut, maka peneliti tertarik untuk meneliti tentang Determinan Kejadian Diare pada Balita di Puskesmas Rawat Inap Simpang Tiga Kota Pekanbaru Tahun 2018.

\section{METODE PENELITIAN}

Penelitian ini bersifat kuantitatif analitik observasional dengan desain case control study. Populasi kasus dalam penelitian ini adalah seluruh balita yang menderita Diare dan tercatat di buku register anak Puskesmas Rawat Inap Simpang Tiga Pekanbaru pada Januari 2017 - April 2018 yang berjumlah 250 orang, sedangkan populasi kontrol yaitu seluruh balita yang tidak menderita ISPA pada tahun yang sama dan tercatat di buku register anak Puskesmas Rawat Inap Simpang Tiga Pekanbaru yang berjumlah 4.161 orang. Kriteria inklusi kasus yang ditetapkan adalah balita yang menderita diare yang tercatat dalam buku register anak di puskesmas, bertempat tinggal di Wilayah Kerja Puskesmas Rawat Inap Simpang Tiga Kota Pekanbaru yang berumur 0 s/d 59 bulan dan memiliki alamat lengkap yang tercatat di buku register anak serta ibu balita yang bersedia menjadi responden. Kriteria inklusi kontrol adalah Balita yang bukan menderita diare yang tercatat dalam buku register anak di puskesmas dalam waktu yang sama dengan kasus, bertempat tinggal di Wilayah Kerja Puskesmas Rawat Inap Simpang Tiga Kota Pekanbaru yang berumur 0 s/d 59 bulan dan memiliki alamat lengkap yang tercatat di buku register anak serta ibu balita yang bersedia menjadi responden. Kriteria eksklusi kasus dan kontrol adalah Ibu balita yang tidak dapat berkomunikasi dan responden tidak dapat ditemui ditempat pada saat penelitian. Sampel dalam penelitian ini terdiri dari sampel kasus dan sampel kontrol. Jumlah sampel pada penelitian ini adalah 195 kasus dan 195 kontrol. Pengambilan sampel kasus dan kontrol dilakukan secara systematic random sampling.

Pengumpulan data dalam penelitian ini menggunakan data primer dan data sekunder. Data primer diperoleh dengan melakukan wawancara dengan menggunakan kuesioner, sedangkan data sekunder diperoleh dari buku register anak Puskesmas Rawat Inap Simpang Tiga Pekanbaru. Variabel-variabel yang digunakan adalah kejadian diare sebagai variabel dependen dengan kategori diare dan tidak diare, sedangkan variabel independen yaitu pemberian ASI Eksklusif dengan hasil ukur tidak ASI Eksklusif dan ASI Eksklusif, Kebiasaan cuci tangan pakai sabun dengan hasil ukur tidak ada kebiasaan dan ada kebiasaan, penggunaan botol susu dengan hasil ukur tidak higiene dan higiene, sumber air minum dengan hasil ukur tidak dimasak dan dimasak, ketersediaan jamban keluarga dengan hasil ukur jamban tidak sehat dan jamban sehat, pengetahuan ibu dengan hasil ukur rendah dan tinggi, pekerjaan ibu dengan hasil ukur rendah dan tinggi, pendapatan ibu dengan hasil ukur rendah dan tinggi, pendidikan ibu dengan hasil ukur rendah dan tinggi serta umur balita dengan hasil ukur beresiko dan tidak beresiko.

$$
\text { Pengolahan data meliputi }
$$

Menyunting data (Editing), Mengkode data (Coding), Memasukkan data (Entry), Membersihkan data (Cleaning), dan Tabulasi data (Tabulating). Analisis data dilakukan secara univariat, bivariat dilakukan dengan uji Chi Square dan 
multivariat dengan menggunakan Regresi Logistik Ganda.

\section{HASIL DAN PEMBAHASAN}

Hasil

\section{Analisis Univariat}

Berdasarkan hasil analisis univariat diperoleh proporsi balita yang tidak diberi ASI Eksklusif sebesar 47,2 \%, Ibu yang tidak ada cuci tangan pakai sabun sebesar $60 \%$, penggunaan botol susu yang tidak higiene sebesar $36,9 \%$, sumber air minum yang tidak dimasak sebesar 63,3\%, ketersediaan jamban keluarga yang tidak sehat sebesar 47,2\%, pengetahuan ibu yang rendah sebesar 29,2\%, ibu yang bekerja sebesar 36,9\%, keluarga dengan pendapatan rendah sebesar 38,2\%, pendidikan ibu yang rendah sebesar 36,4\% dan balita yang berumur $0 \leq 24$ bulan sebesar $47,4 \%$ serta tidak ada data yang homogen (semua kategori $>20 \%$ ).

\section{Analisis Bivariat}

\section{Analisis Bivariat}

Tabel 1 Hubungan antara variabel independen dan variabel dependen kejadian Diare pada balita di Puskesmas Rawat Inap Simpang Tiga Kota Pekanbaru Tahun 2018

\begin{tabular}{|c|c|c|c|c|c|c|c|c|c|}
\hline \multirow{2}{*}{ No } & \multirow{2}{*}{ Variabel Independen } & \multicolumn{2}{|c|}{ Kasus } & \multicolumn{2}{|c|}{ Kontrol } & \multicolumn{2}{|c|}{ Total } & \multirow{2}{*}{$\begin{array}{c}\text { OR } \\
95 \% \mathrm{CI} \\
\end{array}$} & \multirow{2}{*}{$\begin{array}{c}\mathrm{P} \\
\text { Value }\end{array}$} \\
\hline & & $\mathrm{n}$ & $\%$ & $\mathrm{n}$ & $\%$ & $\mathrm{~N}$ & $\%$ & & \\
\hline \multirow[t]{3}{*}{1} & Pemberian ASI Eksklusif & & & & & & & 1,985 & \\
\hline & - Tidak Asi Eksklusif & 109 & 55,9 & 76 & 39 & 185 & 47,2 & $(1,326-$ & 0,001 \\
\hline & - Asi Eksklusif & 86 & 44,1 & 119 & 61 & 205 & 52,6 & $2,9710)$ & \\
\hline \multirow[t]{4}{*}{2} & Kebiasaan Cuci Tangan Pakai & & & & & & & & \\
\hline & Sabun & & & & & & & & \\
\hline & - Tidak Cuci Tangan Pakai & 165 & 84,6 & 69 & 35,4 & 234 & 60 & 10,043 & \\
\hline & $\begin{aligned} & \text { Sabun } \\
\text { - } & \text { Cuci Tangan Pakai Sabun }\end{aligned}$ & 30 & 15,4 & 126 & 64,4 & 156 & 40 & $\begin{array}{l}(6,169- \\
16,350)\end{array}$ & $<0,001$ \\
\hline \multirow[t]{3}{*}{3} & Penggunaan Botol Susu & & & & & & & 2,238 & \\
\hline & - Tidak Higiene & 90 & 46,2 & 54 & 27,7 & 144 & 36,9 & $(2,468-$ & $<0,001$ \\
\hline & - Higiene & 105 & 53,8 & 141 & 72,3 & 246 & 63,1 & $3,411)$ & \\
\hline \multirow[t]{3}{*}{4} & Sumber Air Minum & & & & & & & 1,825 & \\
\hline & - Tidak Dimasak & 137 & 70,3 & 110 & 56,4 & 247 & 63,3 & $(1,202-$ & 0,006 \\
\hline & - Dimasak & 58 & 29,7 & 85 & 43,6 & 143 & 36,7 & $2,771)$ & \\
\hline \multirow[t]{3}{*}{5} & Ketersediaan Jamban Keluarga & & & & & & & 1,511 & \\
\hline & - Jamban Tidak Sehat & 102 & 52,3 & 82 & 42,1 & 184 & 47,2 & $(1,013-$ & 0,054 \\
\hline & - Jamban Sehat & 93 & 47,7 & 113 & 57,9 & 206 & 52,8 & $2,254)$ & \\
\hline \multirow[t]{3}{*}{6} & Pengetahuan Ibu & & & & & & & 3,294 & \\
\hline & - Pengetahuan Rendah & 80 & 41 & 34 & 17,4 & 114 & 29,2 & $(2,065-$ & $<0,001$ \\
\hline & - Pengetahuan Tinggi & 115 & 59 & 161 & 82,6 & 276 & 70,8 & $5,256)$ & \\
\hline \multirow[t]{3}{*}{7} & Pekerjaan Ibu & & & & & & & 3,798 & \\
\hline & - Bekerja & 101 & 51,8 & 433 & 22,1 & 144 & 36,9 & $(2,446-$ & $<0,001$ \\
\hline & - Tidak bekerja & 94 & 48,2 & 152 & 77,9 & 246 & 63,1 & $5,897)$ & \\
\hline \multirow[t]{3}{*}{8} & Pendapatan & & & & & & & 2,481 & \\
\hline & - Pendapatan Rendah & 95 & 48,7 & 54 & 27,7 & 149 & 38,2 & $(1,628-$ & $<0,001$ \\
\hline & - Pendapatan Tinggi & 100 & 51,3 & 141 & 72,3 & 241 & 61,8 & $3,779)$ & \\
\hline \multirow[t]{3}{*}{9} & Pendidikan Ibu & & & & & & & 1,406 & \\
\hline & - Pendidikan Rendah & 75 & 38,5 & 60 & 30,8 & 135 & 34,6 & $(0,925-$ & 0,136 \\
\hline & - Pendidikan Tinggi & 120 & 61,5 & 135 & 69,2 & 255 & 65,4 & 2,139) & \\
\hline
\end{tabular}




\begin{tabular}{llllllllll}
\hline 10 & Umur Balita & & & & & & & 1,749 \\
& - Beresiko & 106 & 54,4 & 79 & 40,5 & 185 & 47,4 & $(1,171-$ & 0,008 \\
& - Tidak beresiko & 89 & 45,6 & 116 & 59,5 & 205 & 52,6 & $2,613)$ & \\
\hline
\end{tabular}

Berdasarkan tabel di atas menunjukkan bahwa dari 10 variabel independen ada 8 variabel yang berhubungan signifikan dengan kejadian diare yaitu pemberian ASI Eksklusif pvalue 0,0001 (OR CI 95\% 1,985 :1,3262,9710), kebiasaan cuci tangan pakai sabun pvalue <0,001 (OR CI 95\% 10,043 : 6,169-16,350), penggunaan botol susu pvalue <0,001 (OR CI 95\% 2,238 : 2,468-

\section{Analisis Multivariat}

Tabel 2. Pemodelan Multivariat

\begin{tabular}{llcccc}
\hline No & Variabel & P Value & Exp (B) & \multicolumn{2}{c}{ 95\% CI For EXP (B) } \\
\cline { 4 - 5 } & & & Lower & Upper \\
\hline 1 & Kebiasaan Cuci Tangan Pakai Sabun & 0,000 & 7,977 & 4,610 & 13,804 \\
\hline 2 & Pengetahuan Ibu & 0,082 & 1,696 & 0,936 & 3,074 \\
\hline 3 & Pekerjaan Ibu & 0,000 & 2,656 & 1,600 & 4,408 \\
\hline 4 & Pendapatan & 0,000 & 2,927 & 1,723 & 4,973 \\
\hline 5 & Pendidikan Ibu & 0,028 & 0,514 & 0,283 & 0,932
\end{tabular}

Berdasarkan hasil analisis multivariat variabel independen yang dominan adalah kebiasaan cuci tangan pakai sabun, pendapatan dan pekerjaan ibu. Variabel pendidikan ibu berhubungan terbalik serta variabel pengetahuan ibu merupakan variabel confounding. Adanya variabel yang berhubungan terbalik disebabkan karena adanya bias seleksi.

\section{PEMBAHASAN}

\section{Hubungan Kebiasaan Cuci Tangan Pakai Sabun Kejadian Diare pada Balita}

Hasil penelitian ini menunjukkan bahwa kebiasaan cuci tangan pakai sabun berhubungan sebab akibat dengan kejadian diare dengan pendidikan ibu sebagai variabel confounding. Tidak ada kebiasaan cuci tangan pakai sabun pada ibu
3,411 ), sumber air minum pvalue 0,006 (OR CI 95\% 1,825: 1,202-2,771), pengetahuan ibu pvalue <0,001 (OR CI 95\% 3,294:2,065-5,256), pekerjaan ibu pvalue <0,001 (OR CI 95\% 3,798 : 2,4465,897 ), pendapatan pvalue $<0,001$ (OR CI 95\% 1,825 : 1,202-2,771) dan umur balita pvalue 0,008 (OR CI 95\% 1,749 : 1,1712,613).

.


dibantu oleh orang tua khususnya ibu, sehingga cuci tangan sangat diperlukan oleh seorang ibu sebelum dan sesudah kontak dengan bayi, yang bertujuan untuk menurunkan risiko terjadinya diare pada balita (Wijaya, 2012). Hal ini selaras dengan panduan Depkes RI (2011) yang menyatakan bahwa mencuci tangan yang baik dan benar dapat menurunkan angka kejadian diare sebesar $47 \%$. Oleh karena itu direkomendasikan agar tidak terjadi diare pada balita diharapkan kepada orangtua terutama ibu agar meningkatkan pengetahuan mereka dalam pencegahan diare terutama tentang pentingnya cuci tangan pakai sabun sebelum dan sesudah melakukan aktivitas.

\section{B. Hubungan Pekerjaan Ibu Kejadian Diare pada Balita}

Hasil penelitian ini menunjukkan bahwa pekerjaan ibu berhubungan sebab akibat dengan kejadian diare. Ibu yang bekerja berpengaruh 2,6 kali balitanya menderita diare dibandingkan dengan ibu yang tidak bekerja. Hasil penelitian ini sejalan dengan yang dilakukan oleh Astuti dan Silviana (2015) yang menunjukkan ada hubungan yang signifikan antara pekerjaan ibu dengan kejadian diare pada balita ( $\mathrm{p}$ value $=0,035$ atau $\mathrm{p}$ value < $0,05)$. Ibu yang bekerja balitanya banyak menderita diare karena ibu yang bekerja harus membiarkan anaknya diasuh oleh orang lain atau pengasuh, sehingga anak tersebut mempunyai risiko yang lebih besar untuk terpapar oleh penyakit (Mayasari, 2011). Ibu yang bekerja penuh membuat perhatian terhadap balita berkurang sehingga pemenuhan kecukupan gizi atau pemeliharaan kesehatan anak berkurang (Lasning, 2012). Status gizi berpengaruh sekali pada diare. Pada anak yang kurang gizi karena pemberian makanan yang kurang, episode diare akut lebih berat, berakhir lebih lama dan lebih sering (Ariani, 2016). Oleh karena itu agar balita tidak terkena diare direkomendasikan kepada ibu yang bekerja agar selalu diusahakan memperhatikan dan memantau kesehatan balita supaya balita tidak terkena diare.

\section{Hubungan Pendapatan Kejadian Diare pada Balita}

Hasil penelitian ini menunjukkan bahwa pendapatan berhubungan sebab akibat dengan kejadian diare. Keluarga berpendapatan rendah berpengaruh 2,9 kali balitanya menderita diare dibandingkan keluarga berpendapatan tinggi. Penelitian ini sejalan dengan yang dilakukan oleh Marissa (2015) yang menunjukkan ada hubungan yang bermakna antara variabel pendapatan keluarga terhadap kejadian diare pada balita. Balita dengan orangtua yang pendapatan keluarganya kecil lebih beresiko menderita penyakit diare dibandingkan balita dengan orangtua yang pendapatan keluarganya tinggi $(\mathrm{p}$ value $=$ 0,005 atau $\mathrm{p}$ value $<0,05,95 \% \quad C I=$ 1,627-18,357). Faktor ekonomi mempunyai pengaruh langsung terhadap kejadian penyebab diare, kebanyakan anak yang mudah menderita diare berasal dari kelurga dengan sosial ekonomi yang rendah, daya beli rendah dan kondisi ekonomi yang buruk. Untuk mendukung perawatan kesehatan yang memadai pada anak, cenderung memiliki higiene yang kurang, diet yang kurang, dan pendidikan yang rendah (Agus, dkk, 2009). Oleh karena itu agar tidak terjadi diare pada balita direkomendasikan agar orangtua dapat meningkatkan pendapatan mereka. 


\section{Variabel yang Berhubungan Terbalik dengan Kejadian Diare pada Balita}

\section{Hubungan Pendidikan Ibu Kejadian Diare pada Balita}

Hasil penelitian menunjukkan bahwa ada hubungan terbalik antara variabel pendidikan ibu dengan kejadian diare pada balita. Hal ini disebabkan adanya bias seleksi sehingga hubungan variabel pendidikan ibu dengan kejadian diare pada balita berhubungan terbalik.

\section{KESIMPULAN DAN SARAN}

\section{Kesimpulan}

Berdasarkan uraian pada bab hasil penelitian dan bab pembahasan, maka dengan ini peneliti mengambil kesimpulan

1) Variabel yang berhubungan sebabakibat dengan kejadian diare, yaitu :

a) Kebiasaan cuci tangan pakai sabun : tidak ada kebiasaan cuci tangan pakai sabun pada ibu berpengaruh 7,9 kali balitanya menderita diare dibandingkan dengan ibu yang adakebiasaan cuci tangan pakai sabun (CI 95\% OR=4,755-13,179).

b) Pekerjaan ibu : ibu yang bekerja berpengaruh 2,6 kali balitanya menderita diare dibandingkan dengan ibu yang tidak bekerja (CI 95\% OR = 1,600-4,408)).

c) Pendapatan : keluarga dengan pendapatan rendah berpengaruh 2,9 kali balitanya menderita diare dibandingkan dengan keluarga berpendapatan tinggi $(\mathrm{CI} 95 \%$ OR = 1,723-4,973).

2) Variabel pendidikan berhubungan terbalik dengan kejadian diare pada balita dengan $\mathrm{p}$ value $=0,028$ (CI 95\% $\mathrm{OR}=0,283-0,932$ ).
3) Variabel confounding dalam penelitian ini adalah variabel pengetahuan ibu.

\section{Saran}

1. Disarankan kepada petugas kesehatan agar selalu melakukan penyuluhan rutin sehingga dapat meningkatkan pengetahuan ibu dalam pencegahan diare terutama tentang pentingnya cuci tangan pakai sabun dam air mengalir sebelum dan sesudah melakukan aktivitas dan memberikan informasi melalui media cetak (leaflet, brosur, poster, dll) maupun media elektronik (iklan) cara mencuci tangan pakai sabun yang baik dan benar. Hal ini dilakukan untuk mencegah kejadian diare pada balita.

2. Disarankan kepada pemegang program diare untuk memberikan edukasi tentang cara pencegahan diare kepada keluarga yang berkunjung ke fasilitas kesehatan.

3. Disarankan kepada petugas kesehatan untuk menyampaikan kepada ibu yang bekerja untuk meluangkan waktu membawa balita ke posyandu dan fasilitas kesehatan agar kesehatan balita tetap terpantau dan juga memperhatikan personal higiene balita tersebut. Apabila ibu tidak dapat meluangkan waktu dan balita dititpkan kepada pengasuh, maka pengasuh perlu di beri edukasi dalam menjaga kesehatan balita.

4. Disarankan kepada petugas kesehatan untuk melakukan penyuluhan rutin tentang pencegahan diare pada balita terutama kepada keluarga dengan pendapatan rendah. Selain itu, untuk meningkatkan pendapatan orangtua 
khususnya untuk mereka yang tidak bekerja, perlu dilakukan kegiatan inovatif seperti misalnya melakukan pelatihan dalam mengolah sampah anorganik menjadi benda yang bemanfaat dan mempunyai harga jual sehingga dapat meningkatkan pendapatan mereka.

\section{DAFTAR PUSTAKA}

Dinas Kesehatan Kota Pekanbaru. (2015).

Rekapitulasi Penderita Diare

Menurut Golongan Umur Tahun

2015.

Dinas Kesehatan Kota Pekanbaru. (2016).

Rekapitulasi Penderita Diare

Menurut Golongan Umur Tahun

2016.

Dinas Kesehatan Provinsi Riau. 2014. Rencana Strategis (Resntra) 20142019 Dinas Kesehatan Provinsi Riau.
Hannif. dkk. 2011. Faktor Risiko Diare Akut pada Balita. Kantor Kesehatan Pelabuhan, Padang. Berita Kedokteran Masyarakat Vol. 27, No. 1, Maret 2011.

Kementrian Kesehatan RI. 2013. Riset Kesehatan dasar Tahun 2013.

Kementrian Kesehatan RI. 2013. PokokPokok Hasil Riset Kesehatan dasar Provinsi Riau Tahun 2013.

Syamsudin. 2016. Farmakologi Gangguan Saluran Pencernaan. Jakarta : Penerbit Buku Kedokteran EGC.

Utami, Nurul dan Nabila Luthfiana. 2016. Faktor-Faktor yang Memengaruhi Kejadian Diare pada Anak. Fakultas Kedokteran, Universitas Lampung. MAJORITYI Volume 5 I Nomor 4 I Oktober 2016 I 101 